\title{
A formação profissional em Serviço Social no Brasil: uma trajetória construída por avanços e desafios
}

\author{
Professional training in Social Work in Brazil: a trajectory built \\ by advances and challenges
}

\author{
Melissa Ferreira Portes* \\ Lorena Ferreira Portes**
}

\begin{abstract}
Resumo - O presente artigo apresenta sínteses aproximativas que foram construídas através de estudos e pesquisas realizadas por dois grupos de pesquisa sobre formação profissional em Serviço Social em uma universidade estadual do Paraná. Através de revisão de literatura, o artigo se propõe a recuperar os diferentes projetos formativos que se fizeram presentes na trajetória sócio-histórica do Serviço Social brasileiro. Partindo das diretrizes curriculares de 1996, problematiza a formação graduada, levando em considerando a tendência privatista que predomina no ensino superior brasileiro e que traz repercussões na formação profissional em Serviço Social. Aponta elementos para adensar o debate sobre o tema em questão, reafirmando a tarefa de se formar assistentes sociais considerando a dupla natureza da profissão: analítica e interventiva.
\end{abstract}

Palavras-chave: Serviço Social; formação profissional; exercício profissional; natureza analítica e interventiva.

\begin{abstract}
This article presents approximate summaries that were constructed through studies and research carried out by two research groups on professional training in social work at a state university of $\mathrm{Pa}$ raná, Brazil. Through a literature review, the article proposes to recover the different formative projects that were present in the socio-historical trajectory of Brazilian social work. Starting from the curricular guidelines of 1996, it problematizes the graduate course structure, taking in consideration the tendency to privatize that predominates in Brazilian higher education and that brings repercussions in the professional formation in social work. It points out elements to deepen the debate on the subject in question, reaffirming the task of training social workers considering the dual nature of the profession: analytical and interventional.
\end{abstract}

Keywords: social work; professional training; professional practice; analytical and interventional nature.

\footnotetext{
* Assistente Social. Docente do Departamento de Serviço Social da Universidade Estadual de Londrina (UEL). Coordenadora do Grupo de Pesquisa e Estudo em Formação e Trabalho Profissional (GEFORT) e Coordenadora do setor de estágio supervisionado. Correspondência: Rodovia Celso Garcia Cid, Pr 445 Km 380 - Campus Universitário. Londrina - PR. Cx. Postal 10.011. CEP 86.057-970. Email: <melissaportes2010@gmail.com>.

** Doutora em Serviço Social e Política Social pela Universidade Estadual de Londrina - UEL (2016). Professora do Departamento de Serviço Social da Universidade Estadual de Londrina. Coordenadora do Grupo de Estudos e Pesquisas sobre Formação Profissional em Serviço Social (GEPFOR). Correspondência: Rodovia Celso Garcia Cid, Pr 445 Km 380 - Campus Universitário. Londrina - PR. Cx. Postal 10.011. CEP 86.057-970. Email: <lorenafportes@gmail.com>.
} 


\section{ReVistg all paltt}

\} A FORMAÇÃO PROFISSIONAL EM SERVIÇO SOCIAL NO BRASIL - PORTES, M. F., PORTES, L. F. \} DOI: $10.12957 /$ REP.2017.32748

\section{Introdução}

O artigo apresentado é fruto das discussões realizadas por dois grupos de pesquisa sobre formação profissional em Serviço Social, ambos desenvolvidos em uma universidade estadual do Paraná. Tem por finalidade, através de uma revisão de literatura, apontar elementos para fomentar o debate acerca da formação profissional em Serviço Social, recuperando a trajetória da formação de assistentes sociais no Brasil e apresentando os distintos projetos formativos que se fizeram presentes nesta trajetória.

Para problematizar os caminhos da formação profissional em Serviço Social, realiza-se uma análise considerando o panorama do ensino superior brasileiro, de modo a apontar algumas tendências presentes e que repercutem na formação de assistentes sociais, considerando o caráter privatista predominante das Instituições de Ensino Superior (IES) que ofertam os cursos de Serviço Social.

O texto se encerra com a apresentação de elementos considerados fundamentais para se pensar a formação profissional e que merecem ser aprofundados pela categoria profissional, particularmente para os sujeitos envolvidos com a formação de assistentes sociais.

\section{Os diferentes projetos formativos na trajetória sócio-histórica do Serviço Social brasileiro}

No contexto da gênese da profissão no Brasil, na década de 1930, a formação profissional dos primeiros assistentes sociais foi tributária da influência do humanismo cristão e do neotomismo. Uma formação profissional com forte influência da doutrina social da Igreja Católica e do modelo formativo franco-belga. Esta formação doutrinal era tida como necessária para fornecer aos assistentes sociais uma concepção de vida, de homem e de mundo fundamentada em princípios cristãos. Para assegurar a formação dos agentes sociais nesta perspectiva, as escolas de Serviço Social atuariam para "desenvolver a personalidade dos alunos, garantir a formação profissional, dando-lhes o conhecimento dos problemas sociais e a técnica do trabalho a ser realizado nesse terreno" (FERREIRA, 1939, p. 3).

A profissão era entendida como sendo uma vocação, uma filosofia de vida embasada numa concepção religiosa. A finalidade da formação estava voltada para construir uma carreira baseada na dedicação e desinteresse, buscando restaurar a vida social dos seus irmãos, estando sensível aos seus problemas. O papel do Serviço Social era ajudar na restauração da ordem social cristã, através de um trabalho com técnica, mas também de coração, pois sua atividade deveria ser a de um apostolado de caridade.

Para Ferreira (1939), no processo de formação dos assistentes sociais era preciso levar em consideração quatro aspectos: formação cien- 


\section{Revistg all paUtg}

\} A FORMAÇÃO PROFISSIONAL EM SERVIÇO SOCIAL NO BRASIL - PORTES, M. F., PORTES, L. F. \}

DOI: $10.12957 /$ REP. 2017.32748

tífica, técnica, prática e pessoal. Segundo Sá (1995), a formação deveria fundamentar-se em critérios exigentes em termos da personalidade das assistentes sociais, importando não só o preparo técnico, mas moral. A formação e o ensino em Serviço Social serão envolvidos nesta perspectiva, direcionados para formar profissionais que intervenham de forma moralizadora, de caráter individualizado e psicologizante, na qual os problemas sociais são concebidos como disfunções sociais, julgadas moralmente segundo uma concepção de normalidade dada pelos valores cristãos (BARROCO, 2008). Exigem-se, então, certas qualidades indispensáveis ao agir do assistente social, que deve estar em consonância com os princípios de sua doutrina, a qual não se deve só conhecer, mas muito mais-viver. E que princípios seriam estes? O da justiça e da caridade.

Se, até meados dos anos 1940, a formação profissional era essencialmente doutrinária, e as escolas, em sua maioria, estavam vinculadas ao bloco católico, nos anos 1950 a formação era direcionada para a técnica especializada. A linguagem doutrinária e o conhecimento aristotélico-tomista continuaram rebatendo e influenciando o currículo das escolas, mas uma outra racionalidade foi se apresentando: a linguagem positivista-funcionalista. A partir da interferência política e econômica dos Estados Unidos da América (EUA) no Brasil, através de diferentes acordos estabelecidos entre os governos, ocorreu o intercâmbio do Serviço Social norte-americano com o latino-americano. Por meio deste, as Escolas de Serviço Social da América Latina receberam convites do governo dos EUA para participarem da Conferência Nacional de Serviço Social, que foi realizada em Atlantic City, sendo promovida pela American Association of Schools, em 1941.

Desta primeira aproximação resultou um programa de bolsas de estudos para assistentes sociais sul-americanas, visando ao aperfeiçoamento e à especialização em escolas de Serviço Social norte-americanas. Alimentado pela busca de uma metodologia para o Serviço Social, o seu ensino passou a ser influenciado pelo modelo norte-americano, trazido para o Brasil pelas profissionais que participaram do aperfeiçoamento nos EUA e através de tradução de livros. Ocorreu, desta forma, uma importação dos métodos e das técnicas do Serviço Social de casos, inicialmente e, depois, do Serviço Social de grupo e do desenvolvimento de comunidade. Importante frisar que, nos EUA, o Serviço Social de casos foi o mais desenvolvido no período das bolsas, destacando-se as obras de Mary Richmond e Gordon Hamilton.

A formação profissional, neste contexto, calcou-se na cientificidade e teve por objetivo compreender as perturbações de ordem econômica ou de ordem jurídico-social para auxiliar o indivíduo a realizar sua vida. A "prática profissional" ancorou-se em teorias comportamentais e teorias da personalidade. Essa influência expressou-se no processo formativo através dos projetos pedagógicos e, particularmente, da organização da estrutura curricular. Os assistentes sociais precisavam ser formados dentro dessa racionalidade, buscando conhecer as causas que originavam os desajustamentos 


\section{hevigtg all pgutg}

\} A FORMAÇÃO PROFISSIONAL EM SERVIÇO SOCIAL NO BRASIL - PORTES, M. F., PORTES, L. F. \}

DOI: $10.12957 /$ REP.2017.32748

dos indivíduos e de suas famílias, assim como identificar as causas do desajustamento do ambiente social. Preocupavam-se em centrar seu foco de atuação na personalidade do cliente, buscando mudar seus comportamentos e atitudes, no sentido de ajustá-lo ao meio social para que pudesse cumprir seu papel no sistema vigente.

Eivada da perspectiva modernizadora, a formação profissional nas décadas de 1960 até 1970 foi se adequando para atender às exigências postas pelos processos sociopolíticos emergentes no pós-64, dotando a profissão de um cariz tecnocrático, inserindo-a numa moldura teórica e metodológica exigida pela racionalidade burocrática das reformas promovidas pelo Estado ditatorial (NETTO, 2009). Na conjuntura do final de 1960, estendendo-se nas décadas subsequentes, a profissão foi objeto de análise e reflexão, explicitando seu vínculo com a proposta desenvolvimentista e problematizando seu referencial teórico-metodológico.

Assim, em fins da década de 1970 e início da de 1980, a formação profissional do assistente social passou a ser questionada, iniciando um ciclo de debates sobre a questão. Esse período representou um marco histórico significativo para o Serviço Social brasileiro, uma vez que explicita a construção de um processo de "revisão profissional", tanto no âmbito da formação quanto do exercício profissional, entrelaçado à conjuntura socioeconômica e política brasileira, que incide, diretamente, nos processos organizativos e formativos dos assistentes sociais, no contexto de Ditadura Militar.

A proposta de reforma curricular que se iniciou em 1978 e culminou no currículo de 1982 significou um avanço para o processo formativo na medida em que buscou romper com a perspectiva de análise predominante no Serviço Social, a-classista e a-histórica, tomando como referência a realidade social. Carvalho, Bonetti e lamamoto (1984) consideram que este projeto de formação, que vai se forjando, precisa assumir uma direção social vinculada aos interesses coletivos das classes subalternas.

No clamor do período de efervescência política, o currículo de 1982 do curso de Serviço Social foi aprovado como fruto de um processo de revisão curricular promovido pela então Abess, em 1979, tendo como marco a XXI Convenção Nacional da Abess. Dessa forma, ficou estabelecido, para implantação do novo currículo em todas as unidades de ensino, o prazo máximo de agosto de 1984.

Questionaram-se as diretrizes da formação profissional, seus objetivos e conteúdos, a estrutura curricular, os estágios e a supervisão. Esse processo teve como respaldo a organização política da categoria profissional. Este currículo traduziu o movimento de apreensão do significado sóciohistórico da profissão, vinculando o exercício profissional a uma perspectiva de transformação da realidade. Categorias como conscientização, organização e mobilização das classes populares foram inseridas nos ementários e na organização curricular como um todo, na tentativa de superar o marco 


\section{ReVistg all pgutg}

\} A FORMAÇÃO PROFISSIONAL EM SERVIÇO SOCIAL NO BRASIL - PORTES, M. F., PORTES, L. F. \}

DOI: $10.12957 /$ REP. 2017.32748

das clássicas metas de assistência e promoção (KAMEYANA, 1989). A crítica mais contundente proferida por essa proposta curricular foi à suposta neutralidade profissional.

Tal currículo, fruto do processo de revisão curricular organizado pela Abess, representou um marco histórico na formação profissional ao propor uma reflexão sobre a concepção de formação profissional, buscando construir uma avaliação crítica e propondo um novo encaminhamento metodológico da discussão, que, segundo Carvalho, Bonetti e lamamoto (1986), parte de uma concepção de formação profissional que considere: preparação científica dos quadros profissionais para responder às demandas sociais que se colocavam para o Serviço Social; produção de conhecimentos; e capacitação continuada da categoria em termos de atualização para o exercício profissional.

Este projeto educacional da formação profissional considerou os determinantes estruturais e conjunturais no contexto das relações sociais no bojo do desenvolvimento do capitalismo monopolista. Entendia-se que era preciso ter um posicionamento político e crítico diante das contradições inerentes ao modo de produção capitalista para saber ler e interpretar as demandas e possibilidades que se colocavam à profissão, construindo estratégias interventivas e analíticas.

Houve um compromisso com a transformação da realidade social ao reconhecer a contradição e a luta de classes como categorias estruturantes dessa realidade. Além disso, o mito da neutralidade profissional foi questionado, dando densidade à formação política dos assistentes sociais ao considerar que era preciso investir na formação teórica e metodológica dos profissionais, superando o tecnicismo e a racionalidade instrumental que permearam a preparação e qualificação até os anos 1980.

Em que pese todos os avanços e conquistas construídas com o currículo de 1982, no esforço de se romper com o Serviço Social tradicional, as análises tecidas de sua implantação e alcance social e político na formação profissional indicam que o mesmo não conseguiu materializar as premissas analíticas e metodológicas que tinha proposto. Por isso, a revisão curricular não se esgotou, mesmo com a definição e implantação do novo currículo de 1982, uma vez que o processo de avaliação e acompanhamento da implantação sempre buscou responder aos desafios que se apresentaram para o ensino do Serviço Social.

A década de 1990 representa um momento de redesenho para a compreensão, direção e organização pedagógica da formação profissional em Serviço Social no Brasil, expressando uma síntese dos debates, problematizações e pesquisas que foram sendo construídas no e pelo percurso da categoria profissional e das entidades representativas da profissão. As diretrizes curriculares, construídas em 1996, expressam a defesa de um novo projeto de formação profissional na afirmação das "dimensões interventivas e investigativas como princípios formativos e condição central da formação 


\section{hevigtg all pgutg}

\} A FORMAÇÃO PROFISSIONAL EM SERVIÇO SOCIAL NO BRASIL - PORTES, M. F., PORTES, L. F. \}

DOI: $10.12957 /$ REP.2017.32748

profissional e da relação teoria-realidade" (ABESS, 1997, p. 63). Instaurase, assim, uma nova lógica curricular com base na articulação de "um conjunto de conhecimentos indissociáveis que se traduzem em núcleos de fundamentação, constitutivos da formação profissional" (ABESS, 1997, p. 63).

O processo de revisão curricular ocorreu através de um sucessivo debate na categoria profissional, buscando reafirmar os avanços do currículo anterior, bem como apontar e aprofundar novos elementos para se pensar a formação profissional pautada numa matriz teórica analítica crítica, a teoria social de Marx. Assim, tendo como finalidade avaliar, profundamente, o processo de formação profissional em face às exigências que se apresentavam, as entidades representativas da profissão promoveram um intenso trabalho de mobilização das unidades de ensino de Serviço Social no Brasil, que culminou na elaboração e apresentação das Diretrizes Curriculares para o curso de Serviço Social' ${ }^{1}$.

A proposta curricular da Abess organiza-se em eixos formativos: estruturantes e transversais. Os eixos estruturantes são considerados aqueles fundamentais, os pilares da formação, que devem dar a direção e a sustentação teórica, ética e política do processo formativo. Traduzem questões próprias do modo de produção capitalista, a produção e reprodução das relações sociais e a sociabilidade burguesa como forma de construir um processo de ensino-aprendizagem que leve em consideração a vida social e as contradições presentes na realidade. Os eixos transversais favorecem a interdisciplinaridade, buscando integrar temas deixados à margem do processo educacional. Possibilitam o acesso a saberes específicos, não ficando restritos a um ou outro componente curricular. São transversais porque pretendem desenvolver conteúdos conceituais, procedimentais e atitudinais, como está explicitado nas direções constitutivas do exercício e da formação profissional: teórico-metodológico, ético-político e técnicooperativo.

Os eixos estruturantes das diretrizes curriculares de formação profissional, nesta lógica curricular, são, portanto, a "questão social" e o trabalho/processos de trabalho, e não a política social, como defenderam alguns assistentes sociais no processo de revisão curricular. Esse ponto também não está livre de polêmicas. Compreende-se, assim, que "a questão social é um elemento que dá concretude à profissão, ou seja, é a sua base de fundação histórico-social na realidade e, que nesta qualidade, portanto, deve constituir o eixo norteador do currículo" (ABESS, 1997, p. 20-21). A profissão é considerada uma especialização do trabalho coletivo, inscrita na divisão social e técnica do trabalho, apontando que o currículo deve se aproximar do cotidiano do trabalho do Serviço Social e das formas contemporâneas de organização e desenvolvimento da sociedade brasileira.

\footnotetext{
1 Tendo em vista a finalidade deste texto, não serão apresentados os ataques do MEC à proposta original das Diretrizes Curriculares.
} 


\section{ReVistg QIII P.עtg}

\} A FORMAÇÃO PROFISSIONAL EM SERVIÇO SOCIAL NO BRASIL - PORTES, M. F., PORTES, L. F. \}

DOI: $10.12957 /$ REP.2017.32748

Ao recuperar a centralidade do trabalho na vida social, busca-se "inserir as formas histórico-contemporâneas do trabalho do Serviço Social na sociedade brasileira" (ABESS, 1997, p. 42), para que seja possível "imprimir uma perspectiva de atualização analítica para a apreensão dos fenômenos que circunscrevem a totalidade da vida social" (ABESS, 1997, p. 42). A finalidade é a de, a partir deste fundamento, atualizar os conhecimentos e habilidades, "visando à apreensão da realidade e a melhor qualificação para a intervenção sobre a mesma" (ABESS, 1997, p. 43). Reafirmam-se os pressupostos da teoria social marxista para o tratamento do ser social enquanto totalidade histórica. Em relação aos eixos transversais da formação, a proposta define a ética, a pesquisa e o estágio.

Tendo por referências estes eixos, o documento Diretrizes gerais para o Curso de Serviço Social, apresentado pela Abess ao MEC, em 1996, apresenta os pressupostos da formação profissional; os princípios e diretrizes da formação profissional; a nova lógica curricular e observações e recomendações. Como pressupostos norteadores da concepção de formação profissional, reafirma-se que a profissão tem, na "questão social", seu âmbito de atuação, numa relação mediatizada pelos processos sócio-históricos e teórico-metodológicos constitutivos do processo de trabalho do Serviço Social, que é determinado pelas configurações estruturais e conjuntais da questão social.

A partir destes pressupostos, tem-se por princípios que fundamentam a formação profissional: a) flexibilidade de organização dos currículos plenos (definição de disciplinas e outros componentes, como oficinas, seminários temáticos, atividades complementares); b) rigoroso trato teórico, histórico e metodológico da realidade social e da profissão, adotando-se uma teoria social crítica (marxista) para apreender essa totalidade social; c) superação da fragmentação de conteúdos na organização curricular; d) estabelecimento das dimensões investigativa e interventiva como princípios formativos e condição central da formação profissional e da relação teoria e realidade; d) padrões de desempenho idênticos para os cursos diurnos e noturnos, com um máximo de quatro horas/aula diárias de atividades nos cursos noturnos; e) caráter interdisciplinar nas várias dimensões do projeto de formação profissional; f) indissociabilidade entre ensino, pesquisa e extensão; g) exercício do pluralismo como elemento próprio da natureza da vida acadêmica e profissional; h) ética como princípio formativo, perpassando a formação curricular; i) indissociabilidade entre estágio e supervisão acadêmica e profissional.

Considera-se que as diretrizes curriculares expressam um salto na análise até então construída no debate sobre a formação profissional no sentido de situar não somente a profissão, mas o seu ensino, nas relações sociais oriundas do modo de produção do capital. Pensar a profissão de Serviço Social e a sua formação requer uma análise da realidade social calcada num referencial teórico que privilegie a totalidade. Pelos princípios 


\section{hevigtg all pgutg}

\} A FORMAÇÃO PROFISSIONAL EM SERVIÇO SOCIAL NO BRASIL - PORTES, M. F., PORTES, L. F. \}

DOI: $10.12957 /$ REP.2017.32748

descritos, definem-se as diretrizes curriculares da formação profissional, implicando numa capacitação teórico-metodológica, ético-política e técnicooperativa para que se possa: apreender criticamente o processo histórico como totalidade; investigar a formação histórica e os processos sociais que conformam a sociedade brasileira, apreendendo suas particularidades; apreender o significado social da profissão, desvelando suas possibilidades; apreender as demandas postas à profissão pelo mercado de trabalho, visando formular respostas ao enfrentamento da questão social; exercer a profissão cumprindo as competências e atribuições previstas na legislação profissional em vigor.

Para dar concretude e materialidade aos pressupostos, princípios e diretrizes, a formação profissional deve estar ancorada num conjunto de conhecimentos indissociáveis, que se traduziram em núcleos de fundamentação: núcleo de fundamentos teórico-metodológicos da vida social; núcleo de fundamentos da formação sócio-histórica da sociedade brasileira; e núcleo de fundamentos do trabalho profissional. A partir desses núcleos, desdobramse os conteúdos, as matérias básicas (disciplinas, seminários temáticos, oficinas, atividades complementares) e dos demais componentes curriculares (como o estágio supervisionado e o TCC). Propõe-se, então, uma "lógica curricular inovadora, que supere a fragmentação do processo de ensino e aprendizagem e permita uma intensa convivência acadêmica entre professores, alunos e sociedade" (ABESS, 1997, p. 63).

\subsection{As tendências do ensino superior brasileiro e as implicações para a formação profissional em Serviço Social}

Pensar a formação profissional em Serviço Social exige, para além de uma análise curricular e de seus pressupostos formativos, a compreensão de que esta se processa e se desenvolve sob as interferências sociais, políticas e econômicas dos tempos históricos. Assim, problematizar a formação, a sua direção, os caminhos percorridos e os desafios a enfrentar pressupõe uma análise não endógena da profissão e de sua formação, mas situando-a num determinado contexto de realidade. Nesse sentido, tem-se como exigência apontar a conjuntura atual no que diz respeito a algumas tendências apresentadas no ensino superior brasileiro.

Na esteira destas discussões, destacam-se duas grandes tendências presentes, mas não exclusivamente, no ensino superior brasileiro: a) privatismo e b) centralidade no ensino. A primeira tendência, o privatismo, revela a penetração da lógica do capital no campo educacional. O privatismo é a marca do ensino superior brasileiro. Esta configuração atende a uma dupla funcionalidade: primeiramente, mantendo os interesses do capital, subordinando-se a eles e, em seguida, parecendo atender "parcialmente" às pressões sociais advindas de certos setores da sociedade, que reivindicavam o acesso ao ensino superior, pleiteando a expansão das vagas e acesso às 


\section{Revistg all paUtg}

\} A FORMAÇÃO PROFISSIONAL EM SERVIÇO SOCIAL NO BRASIL - PORTES, M. F., PORTES, L. F. \}

DOI: $10.12957 /$ REP. 2017.32748

camadas mais pobres da população. Sob o discurso da democratização, mascara-se o viés mercantil e privatista que assenta a política educacional brasileira, sobretudo no ensino superior.

De acordo com Minto (2014), tem-se como estratégia fundamental para as empresas do ramo educacional a concentração de mercado e de capital. Como resultado desta concentração, ocorrem as fusões em que IES menores são compradas pelas maiores, geralmente localizadas no interior do país e com problemas financeiros, formando-se assim grandes grupos. A educação é convertida em mercadoria controlada por poucos grupos, denominando o que Oliveira (2009, p. 752) chamou de "mercadoria oligopolizada". Outra estratégia apontada por Minto (2014) é a penetração de capitais estrangeiros nesse mercado, concretizando-se por meio de associação dos grupos educacionais com o capital financeiro, negociando-se a educação, altamente rentável, na forma de ações em bolsa de valores.

Através dos dados do Censo da Educação Superior de 2015 podese evidenciar essa tendência privatista. Do total de 2365 IES no Brasil, 87,52\% são privadas. Do total de IES, somente 195 são universidades (8,25\%); 149 $(6,3 \%)$ são centros universitários; $40(1,69 \%)$ são caracterizadas como Institutos Federais (IFs) e Cefets; e $1.980(83,76 \%)$ são faculdades. Em relação às IES privadas, o predomínio das faculdades se faz presente. Das 2.069 IES privadas, somente $88(4,25 \%)$ são universidades; $140(6,76 \%)$ são centros universitários e 1.841 (88,99\%) são faculdades. Esta tendência se faz presente, por sua vez, no desenho das IES que ofertam o curso de Serviço Social (nas modalidades presencial e a distância). Caracterizando essas, temse a seguinte descrição, de acordo com o Censo de 2015: 350 IES oferecem o curso de Serviço Social, sendo 61 públicas e 289 privadas; dos 435 cursos oferecidos nestas IES, 61 são em IES públicas e 359 em privadas. Do total de 172.569 matrículas nos cursos de Serviço Social no Brasil, 21.436 estavam em IES públicas e 151.133 matrículas no setor privado (BRASIL, 2015).

Em relação à modalidade de ensino, dos 435 cursos, 409 são oferecidos na modalidade presencial e 26 a distância; dos 409 cursos presenciais, 334 são oferecidos em instituições privadas e 75 em instituições públicas. Dos 334 cursos no setor privado, 91 são oferecidos em universidades, 59 em centros universitários e 184 em faculdades. Esta lógica é diferenciada nos cursos oferecidos na modalidade presencial no setor público: 66 cursos em universidades, 8 em faculdades e 1 em IF. Dos 26 cursos a distância, 25 são ofertados por instituições privadas (18 em universidades e 8 em centros universitários) e 1 em universidade estadual pública (BRASIL, 2015). Os dados confirmam um modelo de ensino superior que tem no mercado a referência e o controle, reafirmando a premissa de que o ensino superior é antes um bem privado do que público, como apontou Sguissardi (2009).

Esse quadro deve ser considerado ao se debater a formação profissional de assistentes sociais, pois um projeto de formação profissional 


\section{hevigtg all pgutt}

\} A FORMAÇÃO PROFISSIONAL EM SERVIÇO SOCIAL NO BRASIL - PORTES, M. F., PORTES, L. F. \}

DOI: $10.12957 /$ REP.2017.32748

não deve ser pensado dissociado da realidade. Isto não significa pensar numa "adaptação" para reforçar os interesses mercantis. No entanto, problematizar a direção da formação, bem como seu projeto formativo, deve considerar esse determinante econômico. Se um dos princípios para a formação, afirmados nas diretrizes curriculares, é a indissociabilidade entre ensino, pesquisa e extensão, como garantir a articulação deste tripé, uma vez que a prevalência das IES que ofertam o curso de Serviço Social é de serem faculdades privadas? Como faculdades, legitimadas pela Lei de Diretrizes e Bases da Educação (LDB), não possuem obrigatoriedade em desenvolverem pesquisa.

Essa questão leva à segunda tendência: a centralidade no ensino. Com forte influência e orientação das agências internacionais, sobretudo do Banco Mundial, ocorre uma mudança no perfil das IES, através de maior diferenciação institucional. Assim, com a criação de instituições não universitárias, consideradas onerosas e pouco sensíveis às necessidades do mercado, reorganiza-se a estrutura triplamente articulada entre ensino, pesquisa e extensão. Desta forma, diferencia-se as IES entre as que fazem pesquisa e IES que concentram suas atividades no ensino. Concorda-se com Minto (2014, p. 342) ao dizer que os processos de flexibilização e de diversificação nas modalidades de ensino "estão amplamente vinculados à lógica da privatização", operando segundo "as mesmas tendências de adequação da educação superior aos novos padrões de acumulação capitalista nos tempos de mundialização".

Como já exposto, do total de IES que ofertam o curso de Serviço Social, $82,57 \%$ são privadas. Nestas IES são oferecidos 334 cursos, sendo que $55 \%$ desses são ofertados em faculdades. Essa marca incita a pensar: como a formação graduada em Serviço Social será orientada de modo a pautar-se nos pressupostos, princípios e diretrizes afirmados nas diretrizes curriculares de 1996? Além disso, essa realidade provoca a problematizar: como estes cursos, que se concentram sobretudo em faculdades privadas e que têm o predomínio de suas atividades pedagógicas no ensino, irão garantir uma formação calcada num rigoroso trato teórico, histórico e metodológico da realidade social e da profissão? Um trato que busque estabelecer uma relação entre as dimensões investigativa e interventiva, que apreenda as demandas postas à profissão, pelo mercado de trabalho, criando respostas interventivas e cumprindo as competências e atribuições previstas nas legislações profissionais?

É preciso considerar as condições objetivas de trabalho dos docentes que formam os assistentes sociais e que estas são diferenciadas nos âmbitos público e privado. Os dados revelam que, enquanto nas IES privadas o "típico docente" possui título de mestre e regime de trabalho horista, nas IES públicas, o "típico docente" possui título de doutor e regime de trabalho em tempo integral. No Brasil, existem 401.299 docentes no ensino superior, sendo que, destes, 226.863 (56,53\%) atuam em IES privadas. Quais as 


\section{Revistg all paUtg}

\} A FORMAÇÃO PROFISSIONAL EM SERVIÇO SOCIAL NO BRASIL - PORTES, M. F., PORTES, L. F. \}

DOI: $10.12957 /$ REP. 2017.32748

condições de trabalho dos assistentes sociais que atuam na formação graduada, seja presencial ou a distância?

Se, através dos dados, identificou-se que os cursos de Serviço Social são ofertados predominante em faculdades privadas, é preciso levar em consideração que as condições de trabalho nestas instituições têm algumas características particulares: concentração das atividades em ensino, através de regime de trabalho horista; restrição e até ausência de carga horária para a pesquisa; dificuldades para a qualificação docente, tendo em vista o regime de trabalho e a liberação para a qualificação profissional, como licenças especiais.

Outra questão a ser inserida no debate sobre a formação profissional é o perfil docente: quem são os assistentes sociais que atuam na docência? Quais seus percursos formativos e profissionais? Como tem sido a sua formação acadêmico-profissional e de que forma esta qualifica e prepara para que eles formem assistentes sociais com um denso trato teórico analítico da realidade e da profissão? Se a pesquisa tem sido restringida nas instituições privadas, sobretudo em faculdades, como o docente, que não experiencia e desenvolve pesquisas acadêmico-científicas, irá contribuir para formar assistentes sociais norteados pela dimensão investigativa? Estes elementos devem ser considerados ao se debater os caminhos da formação profissional em Serviço Social para que não se sobreponha as condições subjetivas às objetivas.

\subsection{Os desafios à formação profissional em Serviço Social: alguns apontamentos}

Como contribuições ao debate sobre a formação profissional em Serviço Social apontam-se elementos que se considera fundamentais, mas não exclusivos; quais sejam:

a) Pautando-se nos pressupostos, princípios e diretrizes para a formação profissional, afirmados nas diretrizes curriculares, defende-se que a formação de assistentes sociais necessita possibilitar uma competência teórico-analítica, em que a realidade social seja apreendida nas suas múltiplas determinações e calcada numa análise da totalidade pela crítica da economia política.

Os conhecimentos teóricos podem contribuir com os profissionais de Serviço Social no sentido de fomentar uma análise mais apropriada e aprofundada da realidade social, orientando o seu exercício profissional, não como manual prescritivo de ações, mas através de elementos que proporcionem essa relação analítico-interventiva. Além disso, também compreendendo as demandas sociais que são postas aos profissionais; analisando o perfil e a funcionalidade das políticas sociais e do Estado; problematizando as respostas institucionais e o direcionamento econômico-político que incide diretamente na vida social dos trabalhadores, nas relações de produção e 


\section{hevigtg all pgutt}

\} A FORMAÇÃO PROFISSIONAL EM SERVIÇO SOCIAL NO BRASIL - PORTES, M. F., PORTES, L. F. \}

DOI: $10.12957 /$ REP.2017.32748

reprodução social, nos processos de aviltamento da exploração e no ataque e regressão dos direitos humano-sociais.

Um referencial teórico-metodológico é analítico e não instrumental. No seu exercício profissional, os assistentes sociais se apropriam de outros tipos de conhecimentos (técnicos, especializados, procedimentais, instrumentais) para responder às demandas do cotidiano profissional. É preciso atentar para o fato de não reduzir um conhecimento oriundo de uma teoria social (que não responde às exigências técnico-instrumentais) ao "fazer profissional" de modo prescritivo e manualesco, eliminando o seu potencial revolucionário.

O marxismo é uma doutrina teórico-prática e não um receituário e instrumento de intervenção profissional. Para tanto, é urgente investir na capacitação e aprimoramento teórico-analítico dos assistentes sociais que atuam na docência, pois como exigir uma formação com esse cariz se os formadores não possuem uma apropriação teórico-metodológica crítica da realidade? A formação precisa ser continuada, sistemática e rigorosa no preparo de docentes qualificados para desenvolverem, como apontam as diretrizes e os princípios das diretrizes curriculares, uma formação que oportunize "rigoroso trato teórico, histórico e metodológico da realidade social e do Serviço Social", tendo por referência uma "teoria social crítica que possibilite a apreensão da totalidade social em suas dimensões de universalidade, particularidade e singularidade" possibilitadora de uma "apreensão crítica do processo histórico como totalidade" (ABESS, 1997, p. 61).

b) É preciso considerar e reforçar que a profissão tem uma dupla natureza " analítica e interventiva " e isso requer uma formação que se sustente em um estatuto teórico-prático. Tal preparo pressupõe o desenvolvimento de um conjunto de conhecimentos e saberes que oportunizem ao sujeito em formação o desenvolvimento de competências e habilidades profissionais capazes de tomar a realidade social como referência e de construir ações profissionais que atendam às demandas socialmente postas no cotidiano profissional. Assim, o exercício e a formação profissionais precisam ser analisados a partir de sua indissociabilidade.

Por isso, a formação profissional não pode se privar de possibilitar a construção de conhecimentos que, dialeticamente articulados, oportunizem uma qualificação teórico-metodológica sem desprezar a natureza interventiva da profissão. É preciso levar em consideração as condições sob as quais o exercício profissional se materializa, refletindo acerca das requisições do mercado de trabalho e as condições objetivas de trabalho; a configuração das políticas sociais e sua funcionalidade, nos marcos de uma sociedade capitalista; as demandas profissionais e a necessidade de sua reconstrução para a assistência das necessidades apresentadas pelos sujeitos atendidos pelo assistente social, buscando, assim, diminuir o distanciamento existente entre a formação e o cotidiano profissional. Sim, porque esse "fosso" existe e desconsiderá-lo é deixar de avançar no debate, na problematização 


\section{ReVistg all pgutg}

\} A FORMAÇÃO PROFISSIONAL EM SERVIÇO SOCIAL NO BRASIL - PORTES, M. F., PORTES, L. F. \}

DOI: $10.12957 /$ REP.2017.32748

do ensino do Serviço Social e dos conhecimentos que precisam ser mobilizados no percurso formativo.

A formação profissional que se afirma progressista não pode virar as costas para a realidade dos campos ocupacionais do assistente social. O conhecimento crítico, tão necessário para o enfrentamento das racionalidades conservadoras, não pode tornar-se sinônimo apenas de denuncismo, mas precisa capacitar o futuro profissional para o exercício das atribuições e competências profissionais definidas pela legislação de regulamentação profissional, mediadas também pelas requisições socioinstitucionais.

Dessa forma, a aproximação com os assistentes sociais que estão materializando o exercício profissional nos diferentes campos sócio-ocupacionais, através de propostas de educação permanente e formação continuada, é imprescindível para que o ensino do trabalho profissional seja problematizado e para que se conheça, com profundidade, as modalidades de intervenção profissional, as ações profissionais construídas e as exigências requeridas. É preciso indagar constantemente qual o lugar que o ensino do trabalho profissional tem ocupado nas estruturas curriculares dos cursos de Serviço Social e quais conhecimentos teórico-práticos precisam ser ensinados e exigidos do estudante em formação para o seu futuro exercício profissional.

Essa postura exige um esforço intelectual da categoria profissional para se debruçar na discussão da particularidade do exercício profissional. Questão essa tão cara aos profissionais, mas que não pode mais ser adiada porque dela decorre o futuro dessa profissão assalariada no contexto contemporâneo.

\section{Considerações finais}

A formação profissional em Serviço Social no Brasil foi orientada no seu percurso sócio-histórico por distintos projetos formativos, que responderam às exigências sociopolíticas e econômicas da sociedade brasileira, mas também se colocaram num movimento de questionamento, de revisão e problematização destas mesmas exigências. As Diretrizes Curriculares (1996) expressam um projeto formativo que foi desenhado e sustentado num contexto de crítica à profissão, em que se coloca em questionamento os componentes teóricos, ideopolíticos e técnicos que orientavam a formação e o exercício profissionais.

Nesse sentido, debater sobre a formação profissional, pautandose nas Diretrizes Curriculares de 1996, requer uma análise articulada entre formação e exercício profissional, retomando-se as exigências ao processo formativo de assistentes sociais, que envolve um conjunto de competências a serem desenvolvidas. Destaca-se, então, dentre estas, a importância de um adensamento teórico analítico na formação que potencialize uma análise crítica e aprofundada da realidade social, em que os assistentes sociais se 


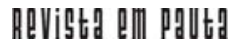

\} A FORMAÇÃO PROFISSIONAL EM SERVIÇO SOCIAL NO BRASIL - PORTES, M. F., PORTES, L. F.

DOI: $10.12957 /$ REP.2017.32748

inserem e atuam, munindo-se de um referencial teórico-crítico para que sejam capazes de apreender esta realidade nas suas múltiplas determinações, interpretando as demandas sociais não como mero epifenômenos.

Mesmo reconhecendo os limites profissionais, não se descarta uma apropriação mais consistente das bases sociais e econômicas que estruturam a sociedade de classes para que seja possível localizar a inserção profissional nesta trama de relações, bem como explicitar as desigualdades sociais que se materializam e se expressam no cotidiano, na realidade social, e analisar as respostas que são dadas para o enfrentamento destas desigualdades.

O adensamento teórico-analítico deve possibilitar ao futuro profissional tomar a realidade social como referência para construir as respostas interventivas de modo a atender às demandas socialmente postas no cotidiano profissional, levando em consideração as condições sob as quais o exercício profissional se materializa, refletindo acerca das requisições do mercado de trabalho e das condições objetivas de trabalho; a configuração das políticas sociais e sua funcionalidade nos marcos de uma sociedade capitalista; as demandas profissionais e a necessidade de sua reconstrução para o atendimento das necessidades apresentadas pelos sujeitos atendidos pelo assistente social. 


\section{ReVistg all paltg}

\} A FORMAÇÃO PROFISSIONAL EM SERVIÇO SOCIAL NO BRASIL - PORTES, M. F., PORTES, L. F. \}

DOI: $10.12957 /$ REP. 2017.32748

\section{Referências}

ABESS. Diretrizes gerais para o curso de serviço social. Cadernos Abess, São Paulo: Cortez, n. 7, 1997.

BARROCO, M. L. Ética e Serviço Social: fundamentos ontológicos. São Paulo, Cortez, 2008.

BRASIL. Instituto Nacional de Estudos e Pesquisas Educacionais Anísio Teixeira. Sinopse Estatísticas da Educação Superior. Brasília, 2015. Disponível em: <http://portal.inep.gov.br/superior-censosuperior-sinopse>. Acesso em: 15 jun. 2017.

CARVALHO, A. M. P. de; BONETTI, D. A.; IAMAMOTO, M. Projeto de investigação: a formação profissional do assistente social. Revista Serviço Social e Sociedade, ano V, n. 14, abr. 1984.

FERREIRA, F. Considerações sobre o Serviço Social. Revista Serviço Social: órgão informativo e doutrinário, São Paulo, n. 1, jan. 1939.

KAMEYAMA, N. Concepção de teoria e metodologia. Cadernos Abess, São Paulo: Cortez, n. 3, 1989.

MINTO, L. W. A educação da miséria: particularidade capitalista e educação superior no Brasil. São Paulo: Outras Expressões, 2014.

NETTO, J. P. Ditadura e Serviço Social: uma análise do Serviço Social no Brasil pós-64. São Paulo: Cortez, 2009.

OLIVEIRA, R. P. A transformação da educação em mercadoria no Brasil. Educação e Sociedade, Campinas, v. 30, n. 108, p. 739-760, out. 2009.

SÁ, J. Conhecimento e currículo em Serviço Social. São Paulo: Cortez, 1995.

SGUISSARDI, V. Universidade brasileira no século XXI: desafios do presente. São Paulo: Cortez, 2009.

DOI: 10.12957/rep.2017.32748

Recebido em 31 de agosto de 2017.

Aprovado para publicação em 05 de dezembro de 2017.

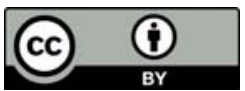

A Revista Em Pauta: Teoria Social e Realidade Contemporânea está licenciada com uma Licença Creative Commons Atribuição 4.0 Internacional. 